
\title{
3 Research Suare \\ Detection of Microplastics in Patients with Colorectal Adenocarcinoma using Various Techniques
}

\section{Meltem ÇETIN}

Ataturk University: Ataturk Universitesi

Fatma DEMIRKAYA MILOĞLU

Ataturk University: Ataturk Universitesi

Nurcan KILIÇ BAYGUTALP ( $\nabla$ eczbaygutalp80@gmail.com )

Atatürk Üniversitesi: Ataturk Universitesi

Onur CEYLAN

Ataturk University: Ataturk Universitesi

Serkan YILDIRIM

Ataturk University: Ataturk Universitesi

Gizem ESER

Ataturk University: Ataturk Universitesi

Halise İnci GÜL

Ataturk University: Ataturk Universitesi

\section{Research Article}

Keywords: ATR-FTIR and Raman spectroscopies, colorectal cancer, health, microplastics, pollution

Posted Date: February 3rd, 2022

DOI: https://doi.org/10.21203/rs.3.rs-1315103/v1

License: (9) This work is licensed under a Creative Commons Attribution 4.0 International License. Read Full License 


\section{Abstract}

Whether microplastic poses a risk to the ecosystem and human health is a matter of concern. The presence of microplastics in tumoral colon tissues (TCT, $n=16$ ) and non-tumoral colon tissues ( $N$-TCT, $\mathrm{n}=16)$ of the patients diagnosed with colorectal adenocarcinoma and also in the colon tissue samples $(C$, $\mathrm{n}=15$ ) collected from subjects not diagnosed with colorectal cancer were determined for the first time. The microplastics were extracted from the colon tissues of TCT, N-TCT, and C groups, and ATR-FTIR and Raman spectroscopies were used for identification. The particle size of microplastic extracted from the colon tissues of TCT, N-TCT, and C groups were in the range of 1 to $1299 \mu \mathrm{m}$. The number of microplastics (in $1 \mathrm{~g}$ colon tissue) extracted from the TCT group was found to be significantly higher than those extracted from the $\mathrm{N}-\mathrm{TCT}(P=0.001)$ or $\mathrm{C}$ groups $(P=0.002)$. The presence of three microplastic polymers [polyethylene (PE), Poly (methyl methacrylate) (PMMA), and nylon (polyamide)] was determined in the spectra of the extracted microplastics via comparison with the spectra in KnowltAll ${ }^{\circledR}$ QC Expert software database. We might propose that there is a link between colorectal cancer and microplastic exposure level.

\section{Introduction}

A significant amount of the plastics produced every year is released into the environment, and the plastics accumulate in the environment due to their low degradability and continuous input. Until 2004, the terminology "microplastics" was not introduced (Pan 2019). Then, the following definition was made for microplastics: "microplastics are polymeric matrix or synthetic solid particles with a regular or irregular shape, of either primary or secondary manufacturing origin". They are insoluble in water, and their particle sizes range between $1 \mu \mathrm{m}-5 \mathrm{~mm}$ (Campanale 2020; Frias 2019).

Nowadays, microplastics are found everywhere in our environment in different shapes, sizes, different polymeric structures, and amounts. The presence of microplastics in drinking water, marine water, agroecosystems, atmosphere, and foods was reported. Humans encounter microplastics mainly through food, the atmosphere, and drinking water. Whether microplastic pollution poses a risk to the ecosystem and human health is a matter of concern (Campanale 2020; Eerkes-Medrano 2019; Wright 2017). However, there is not enough data on this subject yet, and more studies are needed.

Some studies reported that humans are exposed to microplastics via diet (Wright 2017; Stock 2019) or inhalation. These microplastics can lead to the toxicity of localized particles by inducing or enhancing an immune response (Wright 2017). Transport of microplastics through human food chains includes ingestion. The consumption of food sources such as fishes contaminated with microplastics is a concern to human health. Humans consume approximately $5 \mathrm{~g}$ of microplastics a week (Petersen 2021). In a study, microplastics were detected in human stool samples (Schwabl 2019). Recently, in another study, the researchers have analyzed human tissue (liver, lung, spleen, kidney, and adipose tissues) samples by mass spectrometry and determined that there were monomers or plastic constituents in these tissues samples (American Chemical Society 2020). As seen from the literature examples above, microplastics 
have been demonstrated in drinking water, atmosphere, foods, human tissues (only one study), human stool, and such. However, no studies investigating the presence of microplastics in human cancer tissues have been found. Therefore, our aim in this study is to determine the presence of microplastics in the colon tissues (TCT and N-TCT groups) of the patients diagnosed with colorectal adenocarcinoma and also, in the colon tissue samples collected from subjects not diagnosed with colorectal cancer (C), for the first time. For this purpose, first of all, microplastics were extracted from the colon tissues (TCT, N-TCT, and $\mathrm{C}$ groups) and examined using a light microscope, the attenuated total reflection-Fourier-transform infrared (ATR-FTIR) and Raman spectroscopies.

The simultaneous measurement of chemical (i.e. spectroscopic) and physical (i.e. spatial) information was provided by chemical imaging. Thus, it is a promising tool for the analysis of microplastics. FTIR spectroscopy and Raman spectroscopy have been used to identify microplastics in various samples (Araujo 2018; Käppler 2016). FTIR's different operating modes (transmission, ATR, and reflection) are widely used for microplastics analysis. For FTIR spectroscopy, transmission and ATR are the most popular modes, and ATR-FTIR needs minimal sample preparation and is quick (Xu 2019). Raman spectroscopy has advantages, such as non-destructive, environmental friendliness, low sample amount, high-efficiency scanning. Compared to FTIR spectroscopy, Raman spectroscopy shows higher sensitivity to non-polar functional groups, better spatial resolution, narrower spectral bands, broader spectral coverage, and lower water interference (Araujo 2018). It is widely used to identify microplastics due to its fingerprint type analysis, which provides excellent capability in detecting microplastics (Araujo 2018).

\section{Materials And Methods}

\section{Materials}

Nitric acid (65\%) and hydrogen peroxide (30\%) were purchased from Reidal-dehaën (The Netherlands) and JT Baker (Germany), respectively. Sodium chloride ( $\geq \% 99.5$ ) was obtained from Sigma-Aldrich (Germany).

Ethical Issues, the Patients Diagnosed with Colorectal Adenocarcinoma and the Subjects Not Diagnosed with Colorectal Cancer

This study was approved by the Clinical Research Ethics Committee of the Medical Faculty at Ataturk University (Decision Date/No:17.12.2020/B.30.2.ATA.0.01.00-10-50). Human colon resection samples, collected from 16 patients during medically indicated surgery at the University Hospital, were kept in 10\% formaldehyde solution and transported to the Department of Medical Pathology and examined histopathologically. The patients had not been treated with radiotherapy or chemotherapy before surgery. The cases diagnosed with colorectal adenocarcinoma were staged depending on the pathologic staging system ("pTNM; pT: primary tumor size, N: regional lymph nodes, M: distant metastasis"), which is widely used as a cancer staging system. Among colorectal adenocarcinoma patients, 2 (12.5\%), 12 (75\%), and 2 $(12.5 \%)$ of the cases were diagnosed as tumor invaded muscularis propria (pT2), through the muscularis 
propria into the pericolorectal tissues (pT3), and the visceral peritoneum (pT4a), respectively. When the patients diagnosed with colorectal adenocarcinoma were also evaluated in terms of $\mathrm{N}$, it was seen that $10(62.5 \%)$ patients were in the N0 stage (no cancer in nearby lymph nodes), and 6 (37.5\%) patients were in the N1 stage (metastasis in 1-3 lymph nodes). Distant metastasis (liver/M1a) was observed only in 1 $(6.25 \%)$ cases.

The colon tissues (TCT and N-TCT groups) collected from 16 patients diagnosed with colorectal adenocarcinoma were included in this study. Besides, the colon tissue samples collected from 15 subjects not diagnosed with colorectal cancer were also included in this study as a control group (C). The tissue samples were not subjected to tissue processing steps consisting of dehydration, clearing, and infiltration. In other words, the samples were not treated with alcohol, xylene, and paraffin. After their histopathological diagnosis, the TCT, N-TCT, and C colon tissue samples obtained from resection tissue were stored in $10 \%$ formaldehyde solution.

\section{Extraction of Microplastics from the Colon Tissue Samples (For TCT, N-TCT, and C Groups)}

To extract microplastic from the colon tissues samples (for TCT, N-TCT, and C groups), the method described by Deng et al. was used with a slight modification (Deng 2017). It is a reliable method for removing biological matters and the extraction of microplastics from tissue samples. Briefly, the colon tissue samples (for TCT, N-TCT, and C groups) were digested in nitric acid at $70^{\circ} \mathrm{C}$ for $2 \mathrm{~h}$, hydrogen peroxide was added and digested for a further $2 \mathrm{~h}$ at $85^{\circ} \mathrm{C}$. At the end of this period, the volume of the digested solution was completed to $15 \mathrm{~mL}$ with $\mathrm{NaCl}$ solution (for flotation) and stirred on the magnetic stirrer for $30 \mathrm{~min}$ at room temperature (RT). Later, the mixture was stirred on days 2 and 3 for 30 min on the magnetic stirrer at RT. The images of microplastic particles in the medium were obtained on the fourth day using an optical microscope [Olympus BX51 with camera (Olympus DP 72) and DP2-BSW imaging software program, Japan]. Microplastics extracted from the colon tissues obtained from the controls and the patients with colorectal adenocarcinoma were detected and described based on the number and size using the optical microscope.

\section{ATR-FTIR and Raman Analysis of the Microplastics Extracted From the Colon Tissues}

In addition, ATR-FTIR spectroscopy [FT-IR Spectrometer Model IRSpirit Shimadzu (Japan) equipped with the QATR-S (single-reflection attenuated total reflectance measurement attachment), and with LabSolutions IR software] was used to obtain ATR-FTIR spectrum of the microplastics extracted from the colon tissue samples (for TCT, N-TCT, or C groups) to identify the types of microplastics. The ATR-FTIR spectra were recorded in the ranges of $500-4000 \mathrm{~cm}^{-1}$. Furthermore, Raman spectroscopy was used in this study to analyse the extracted microplastics from the colon tissue samples (for TCT, N-TCT, or C groups). The Raman spectra were obtained at 500-4000 cm-1 using WITec Alpha 300R Micro Confocal 
Raman Spectrometer (Burker, Germany) equipped with two laser wavelengths (532 and $758 \mathrm{~nm}$ ) and with OPUS 6.5 software by filtering the Raleigh scattering to give a resolution of $0.5 \mu \mathrm{m}$ using $600 \mathrm{~g} / \mathrm{mm}$.

\section{Statistical Analyses}

The results were expressed as mean \pm standard deviation (SD) and min-max values. Statistical analysis was performed using SPSS version 23.0 (SPSS, Chicago) package program. The normality of data was analyzed with the Kolmogorov-Smirnov test. The independent samples t-test was used to evaluate the statistical significance of the differences between the groups. Values of $P<0.05$ were considered statistically significant (at a $95 \%$ confidence interval).

\section{Results}

In this study, firstly, the microplastics were successfully extracted from the colon tissues (C, TCT, or N-TCT groups) obtained from the controls and the patients diagnosed with colorectal adenocarcinoma. The demographic characteristics of patients diagnosed with colorectal adenocarcinoma and controls are given in Table 1.

Table 1

The demographic characteristics of the patients diagnosed with colorectal adenocarcinoma and the subjects without colorectal cancer (Controls; $\mathrm{C}$ )

\begin{tabular}{|lll|}
\hline & Patients $(\mathbf{n}=16)$ & Controls $(\mathbf{n}=15)$ \\
\hline Age (years) & $60.81 \pm 10.72$ & $65.93 \pm 15.875$ \\
\hline Gender, $\mathrm{n}(\%)$ & Female: $\mathrm{n}=10(62.5 \%)$ & Female: $\mathrm{n}=6(40.0 \%)$ \\
& Male: $\mathrm{n}=6(37.5 \%)$ & Male: $\mathrm{n}=9(60.0 \%)$ \\
\hline Primary tumor size (pT), $\mathrm{n}(\%)$ & PT2: $\mathrm{n}=2(12.5 \%)$ & NA \\
& PT3: $\mathrm{n}=12(75.0 \%)$ & \\
& PT4a: $\mathrm{n}=2(12.5 \%)$ & \\
\hline Survival rate in 3 months, $\mathrm{n}(\%)$ & $\mathrm{n}=14(87.5 \%)$ & NA \\
\hline NA: Not applicable & & \\
\hline
\end{tabular}

An optical microscope was used to determine the size and the number of the microplastics extracted from all groups (TCT, N-TCT, and C). Microplastics were detected in all colon tissue samples (for TCT, NTCT, and $\mathrm{C}$ groups) (Figure 1). The number and size of the extracted microplastic particles were counted visually using the optical microscope, and the results are given in Table 2. 
Table 2

The number and size of the microplastic particles extracted from the colon tissues of all groups.

\begin{tabular}{|lll|}
\hline Groups & $\begin{array}{l}\text { Number of microplastic particles } \\
\text { (in per } \mathbf{1} \text { g colon tissue) }\end{array}$ & $\begin{array}{l}\text { Particle size }(\boldsymbol{\mu m}) \\
\text { (min.-max.) }\end{array}$ \\
\hline TCT $(\mathrm{n}=16)$ & $702.68 \pm 504.26$ & $1-613$ \\
\hline N-TCT $(n=16)$ & $207.78 \pm 154.12$ & $1-743$ \\
\hline C $(n=15)$ & $218.28 \pm 213.05$ & $1-1299$ \\
\hline $\begin{array}{l}\text { TCT: Tumoral colon tissues from the patients diagnosed with colorectal adenocarcinoma; } N-T C T: \\
\text { Non-tumoral colon tissues from the patients diagnosed with colorectal adenocarcinoma; C (Controls): } \\
\text { Colon tissues from subjects not diagnosed with colorectal cancer. }\end{array}$ \\
\hline
\end{tabular}

The sizes of the microplastic particles were in the range of about 1 to $1299 \mu \mathrm{m}$ (Table 2). It has been observed that small particles, especially nanoplastics, form aggregates. There was no significant difference in terms of age between the patient and control groups $(p=0.299)$ (Table 1$)$. When the number of microplastic particles per $1 \mathrm{~g}$ colon tissue was compared between groups, it was seen that there were significant differences between the TCT group and N-TCT $(p=0.001)$ or $C$ groups $(p=0.002)$. However, there was no significant difference between the N-TCT group and the $C$ group $(p=0.876)$ (Table 2$)$.

The ATR-FTIR and Raman spectra of the extracted microplastic particles from the tissues (C, TCT, or NTCT) were obtained in our study, and the baseline and smoothness of the ATR-FTIR and Raman spectra were corrected by the LabSolutions IR software and OPUS 6.5 software, respectively. In our study, the FTIR and Raman spectra taken for all samples in C, N-TCT, and TCT groups were similar. Later, the ATRFTIR and Raman spectra were transferred to KnowltAll ${ }^{\circledR}$ QC Expert software database (Analytical Edition, ID Expert; Bio-Rad Laboratories, Inc.), which is a software and spectral database including the spectra of ATR-FTIR and Raman, for the identification of these particles, and compared with the spectra in the database. Therefore, the representative images were presented to compare ATR-FTIR and Raman spectra (Figures 2 and 3 ).

Figures $2 \mathrm{~A}$ and $2 \mathrm{~B}$ show the comparison of the ATR-FTIR spectra of the extracted microplastic particles from the tissue samples of the TCT, N-TCT, and C groups, obtained in our study with the spectra in the KnowltAll ${ }^{\circledR}$ QC Expert software database. The plastic polymers with a $>80 \%$ match were accepted after the comparison and, consequently, it was observed that three microplastic polymers [PE, PMMA, and nylon (polyamide)], which showed a $>80 \%$ match, were identified using the KnowltAll ${ }^{\circledR}$ QC Expert software database.

Figure 2 shows the characteristic peaks associated with PE in the obtained ATR-FTIR spectra of the microplastic particles extracted from the tissues (C, TCT, or N-TCT). These peaks related to PE are located at $2916,7 \mathrm{~cm}^{-1}\left(\mathrm{CH}_{2}\right.$ asymmetric stretching), $2849,2 \mathrm{~cm}^{-1}\left(\mathrm{CH}_{2}\right.$ symmetric stretching), $1464,16 \mathrm{~cm}^{-1}$ (-C-H bending deformation) and $719,54 \mathrm{~cm}^{-1}$ (-C-H rocking deformation) (Figure $\left.2 \mathrm{~A}\right)$. These results are consistent with the literature (D'Amelia 2016; Gulmine 2002; Lefakane 2015). D’Amelia et al. [14] reported 
that the peaks at $1470 \mathrm{~cm}^{-1}$ and $718 \mathrm{~cm}^{-1}$ are used to identify the presence of PE (D'Amelia 2016). In another study, it was stated that there is a unique characteristic peak (yet quite small) at $1377 \mathrm{~cm}^{-1}$ in the FT-IR spectrum of LDPE (low-density PE), but this peak is not observed in the FT-IR spectrum of HDPE (high-density PE) (Jung 2018). Therefore, our study considered that the microplastic particles extracted from TCT, N-TCT, and C tissues included the HDPE. Besides, in the obtained ATR-FTIR spectra of the microplastic particles extracted from the tissues (C, TCT, or N-TCT groups), the peaks related to PMMA were observed at about $937 \mathrm{~cm}^{-1}$ (bending of $\mathrm{C}-\mathrm{H}$ ), about $1234 \mathrm{~cm}^{-1}$ (C-O stretching vibration), and about $1701 \mathrm{~cm}^{-1}$ ( $\mathrm{C}=0$ stretching) (Figure 2A). These results are consistent with the literature (Duan 2008; Vijayakumari 2013; Haris 2010). The $C=0$ stretching peaks usually fall between 1600 and 1900 $\mathrm{cm}^{-1}$ (Haris 2010; Sigma Technical Document). Furthermore, the peaks between about 2800 and 3000 $\mathrm{cm}^{-1}$ ( $\mathrm{CH}_{2}$ stretching), at about $1542 \mathrm{~cm}^{-1}$ (Amide-Il, $\mathrm{N}-\mathrm{H}$ bending), and about $1464 \mathrm{~cm}^{-1}\left(\mathrm{CH}_{2}\right.$ bending) were assigned to nylon (polyamide) (Figure 2B). These results are supported by the literature (Jung 2018; Vasanthan 2012).

Figures $3 \mathrm{~A}$ and $3 \mathrm{~B}$ show the comparison of Raman spectra of the extracted microplastic particles from the tissues (C, TCT, or N-TCT groups) we obtained in our study, with the spectra in the KnowltAll@ QC Expert software database. It was observed that three microplastic polymers [PE, PMMA, and nylon (polyamide)], which showed a $>80 \%$ match, were identified using the KnowltAll $@$ QC Expert software database. It was observed the peaks related to $\mathrm{PE}$ at $1064 \mathrm{~cm}^{-1}$ (asymmetric $\mathrm{C}-\mathrm{C}$ stretching), at 1126 $\mathrm{cm}^{-1}$ (symmetric $\mathrm{C}-\mathrm{C}$ stretching), at $1440 \mathrm{~cm}^{-1}$ (CH2 bending), at $1297 \mathrm{~cm}^{-1}$ (CH2 twisting), at $2851 \mathrm{~cm}^{-}$

1 (symmetric $\mathrm{CH} 2$ stretching), and at $2883 \mathrm{~cm}^{-1}$ (asymmetric $\mathrm{CH} 2$ stretching). These findings are supported by the literature (Käppler 2016; Kida 2016) at $2723 \mathrm{~cm}^{-1}$ attributed to C-H symmetric stretching, at $1374 \mathrm{~cm}^{-1}$ assigned to $\mathrm{CH} 2$ deformation (Haris 2010). Moreover, $2927 \mathrm{~cm}^{-1}(\mathrm{CH} 2$ asymmetric stretching) $2884 \mathrm{~cm}^{-1}$ (CH2 symmetric stretching), $1635 \mathrm{~cm}^{-1}$ (Amide I), $1126 \mathrm{~cm}^{-1}$ (C-C stretching) bands were related to nylon (polyamide) (Figure 3B), conformed to the literature (Käppler 2016; Menchaca 2003). Besides, in our study, the extracted microplastic particles from the tissues (C, TCT, or N-TCT groups) were photographed by Raman spectroscopy (Figure 3A).

\section{Discussion}

In this study, we investigated the presence of microplastics in tumoral and non-tumoral colon tissues of the patients diagnosed with colorectal adenocarcinoma and the colon tissue samples collected from subjects not diagnosed with colorectal cancer for the first time in the literature.

Microplastics are a growing concern and an important environmental health problem. Microplastics have been detected in rivers, oceans, soil, sewage, sediments, drinking water, and different food sources such as fish, table salt, human stool, and human tissues (Schwabl 2019; American Chemical Society 2020; Deng 2017; Yong 2020). Exposure of MPs on humans and marine organisms has been documented. Especially, plastic particles $<5 \mathrm{~mm}$ in diameter pose a health hazard to human populations (Deng 2017;Yong 2020). The effects of acute and chronic nanoplastics/microplastics exposure on the cells and 
tissues of mammals (especially humans) are yet unclear. Some recent scientific findings have increased the worry of possible tissue penetration and adverse effects of nanoplastics/ microplastics due to their small sizes. Human exposure to them occurs mainly by ingestion, due to microplastics found in food or derived from the packaging of food (plastic bags, plastic bottles, etc.), and also through less defined inhalation (Yong 2020).

Colorectal cancer, the third most common cancer with one to two million new cases being diagnosed every year, is the fourth leading cause of cancer deaths worldwide, despite advances in screening, diagnosis, and treatment (Galissier 2016; Mármol 2017). More than $90 \%$ of colorectal carcinomas are adenocarcinomas. Adenocarcinomas originate from the epithelial cells of the colorectal mucosa (Fleming 2012). The risk factors for colorectal cancer are age, the presence of some diseases (ulcerative colitis, Crohn's disease, inflammatory bowel disease, etc.), a familial history that can be derived from inherited mutations or the environment, dietary and physical activity habits (Mármol 2017).

In our study, the microplastic particles extracted from the colon tissues of TCT, N-TCT, and C groups had in the range of 1 to $1299 \mu \mathrm{m}$ particle size. This wide particle size range is thought to arise from the aggregation of particles, especially nanoplastics. Especially, microplastics with particle sizes of less than $150 \mu \mathrm{m}$ can be absorbed by the human intestine, and therefore the size range is of great importance (EFSA 2016). We also determined that the number of microplastics (in $1 \mathrm{~g}$ colon tissue) extracted from the TCT group was significantly higher than the number of microplastics (in $1 \mathrm{~g}$ colon tissue) extracted from the N-TCT or $\mathrm{C}$ groups. Therefore, oral exposure to microplastic particles and their accumulation in tissues may pose health risks to humans.

Stock et al. [6] reported that humans are exposed to microplastics via diet and, therefore, investigated the uptake and effects of microplastics (fluorescent polystyrene particles with particle size 1, 4, and $10 \mu \mathrm{m}$ ) in Caco-2 cell line (human intestinal epithelial cell line) and in mice in vivo (Stock 2019). Male Hmox1 reporter mice were treated with polystyrene particles by oral gavage (3 times/week for 28 days). This study showed that the cellular uptake of a small fraction of polystyrene particles and that these particles did not cause inflammatory responses and lesions in mice. As a result, they reported that oral exposure to polystyrene particles under selected experimental conditions did not lead to an acute health risk to mammals (Stock 2019). However, this study was conducted on Caco-2 cell lines and mice, and also it was a short-term study to assess the risks of microplastic exposure on health.

On the other hand, Wright and Kelly reported that microplastics could bioaccumulate when ingested or inhaled and lead to the toxicity of localized particles by inducing or enhancing an immune response (Wright 2017). Chronic exposure to microplastics and the degree of their accumulation are predicted to be of greater concern. Microplastics can affect human health, so evaluating exposure levels and burdens is crucial.

In our study, ATR-FTIR and Raman spectroscopies were used to identify microplastics extracted from colon tissues of TCT, N-TCT, and C groups and the obtained ATR-FTIR and Raman spectra of the 
extracted microplastics were compared with the spectra in the KnowltAll ${ }^{\circledR} \mathrm{QC}$ Expert software database. It was observed that three microplastic polymers [PE, PMMA, and nylon (polyamide)], which showed a $>80 \%$ match, conformed to the literature (Käppler 2016; D'Amelia 2016; Gulmine 2002; Lefakane 2015, Haris 2010; Kida 2016; Thermofisher Application Note; Menchaca 2003).

The most common plastic polymer types in the marine environment are PE (HDPE and/or LDPE), polypropylene, polystyrene, polyamide, polyethylene tetraphtlate, polyvinyl chloride, and polyesters. These plastics are used to produce many products, such as milk and juice jugs, netting, plastic bags, bottles, drinking straws, and nylon fabric (Smith 2018). Barboza et al. investigated the presence of microplastics in three commercial fish species (total of 150 fish) from the North-East Atlantic Ocean and found that $49 \%$ of the fish had microplastics (Barboza 2020). Microplastics were found in the gills, gastrointestinal tract, and dorsal muscle of fish. They analyzed microplastics with ATR-FTIR and determined the most common polymers were polyethylene ( $80 \%)$ and polyester (19\%). It has been highlighted that fish consumption is one of the routes humans are exposed to microplastics. Thus, further research is needed to determine risk assessment and minimize human exposure to microplastics (Barboza 2020).

Mak et al. investigated the physical features and numbers of microplastic in the gastrointestinal tracts and gills of the fish in the harbor area (Mak 2020). They used the nitric acid digestion method to obtain microplastics from the gastrointestinal tracts and gills of the fish. They found that the microplastics in the tissues were identified as PE and polypropylene and had mainly fiber form. In another study, 400 individual fish were investigated in terms of ingestion of $>20 \mu \mathrm{m}$ microplastic. It was shown that microplastics include PMMA using FTIR spectroscopy (Hermsen 2017). Microplastics, such as polypropylene, polyethylene, polyamide, and polyethylene terephthalate, were detected in human stool samples (Schwabl 2019). PE was the most common polymer found in sea and lake salt, as well as in drinking water, which is considered one of the possible routes of human exposure to microplastics (Danopoulos 2020; Koelmans 2019).

It was reported that ingested microplastics by mice could be found in the gut, kidney, and liver. Pathological changes to the gut of mice include a gut barrier dysfunction, gut microbiota dysbiosis, reduction in mucus secretion, and intestinal inflammation (Yong 2020). Li et al. investigated the effect of exposure to polyethylene microplastics in a C57BL/6 mice model (Li 2020). They observed that the duodenum and colon of mice fed high concentration polyethylene microplastics developed inflammation and higher expression of AP-1, TLR4, and IRF5. They stated that microplastics could induce intestinal inflammation and dysbacteriosis. Our results can significantly contribute to the available few studies in the literature investigating the presence of microplastic in human tissues or stool and the potential effects of microplastic on human health.

\section{Conclusion}

Our study is the first study reporting microplastic presence in tumoral and non-tumoral colon tissues from patients diagnosed with colorectal adenocarcinoma and comparing with the results obtained from the 
colon tissue samples collected from subjects not diagnosed with colorectal cancer. Our study determined that the number of microplastics extracted from the TCT group was significantly higher than the number of microplastics extracted from the N-TCT or C groups. The results of our study suggest that there may be a connection between colorectal cancer and microplastic exposure level. However, the obtained results in our study should be supported by further studies involving a more significant number of patients and control groups.

\section{Abbreviations}

ATR-FTIR

Attenuated total reflection-Fourier-transform infrared

C

Control

$\mathrm{N}$

Regional lymph nodes

$\mathrm{N}-\mathrm{TCT}$

non-tumoral colon tissue

PE

Polyethylene

PMMA

Poly (methyl methacrylate)

pT

Primary tumor size

TCT

Tumoral colon tissue

\section{Declarations}

\section{Funding}

The authors declare that no funds, grants, or other support were received during the preparation of this manuscript.

\section{Competing Interests}

The authors have no relevant financial or non-financial interests to disclose.

\section{Author Contributions}

All authors contributed to the study conception and design. Material preparation, data collection and analysis were performed by Meltem ÇETIN, Fatma DEMIRKAYA MILOGLU, Nurcan KILIÇ BAYGUTALP, Onur CEYLAN, Serkan YILDIRIM and Gizem ESER. The first draft of the manuscript was written by 
Meltem ÇETIN and all authors commented on previous versions of the manuscript. All authors read and approved the final manuscript.

\section{Data Availability}

The datasets generated during and/or analysed during the current study are available from the corresponding author on reasonable request.

\section{Highlights}

1. The first study reporting microplastic presence in tumoral (TCT) and non-tumoral (N-TCT) colon tissues from patients diagnosed with colorectal adenocarcinoma

2. The presence of three microplastic polymers [PE, PMMA, and nylon (polyamide)] were determined in the colon tissue samples.

3. There may be a connection between colorectal cancer and microplastic exposure level.

Funding: This research did not receive any grant from public or commercial funding agencies (not applicable).

Ethics Committee Approval: This study was approved by the Clinical Research Ethics Committee of the Medical Faculty at Ataturk University (Decision Date/No :17.12.2020/B.30.2.ATA.0.01.00-10-50).

Informed Consent: Not applicable for this study.

Author Contributions: Concept - MC; Design - MC, FDM, NKB; Supervision - MC, FDM, NKB; Resources MC, FDM, NKB; Materials - MC, FDM, NKB, OC; Data Collection and/or Processing - MC, FDM, NKB, OC, SY, GE, HIG; Analysis and/or Interpretation - MC, FDM, NKB; Literature Search - MC, FDM, NKB; Writing Manuscript - MC, FDM, NKB; Critical Review -MC, FDM, NKB, OC, SY, GE, HíG.

\section{References}

American Chemical Society (ACS). Virtual conference 17 August 2020, Press release availableat:https://www.acs.org/content/acs/en/pressroom/newsreleases/2020/august/micro-andnanoplastics detectable-in-human-tissues.html (2020).

Araujo CF, Nolasco MM, Ribeiro AMet al. (2018) Identification of microplastics using Raman spectroscopy: Latest developments and future prospects. Water Research 142: 426-440. 
Barboza LGA, Lopes C, Oliveira P et al. (2020) Microplastics in wild fish from North East Atlantic Ocean and its potential for causing neurotoxic effects, lipid oxidative damage, and human health risks associated with ingestion exposure. Science of the Total Environment 717: 134625.

Campanale C, Massarelli C, Savinol et al (2020) A Detailed Review Study on Potential Effects of Microplastics and Additives of Concern on Human Health. Int J Environ Res Public Health 17:1212.

Eerkes-Medrano D, Leslie HA, Quinn B (2019) Microplastics in drinking water: A review and assessment. Current Opinion in Environmental Science \& Health 7: 69-75.

Frias J, Nash R (2019) Microplastics: Finding a consensus on the definition. Mar Pollut Bull 138: (2019) 145-147.

Danopoulos E, Jenner L, Twiddy M et al. (2020) Microplastic contamination of salt intended for human consumption: a systematic review and meta-analysis. SN Applied Sciences 2: 1-18.

Deng Y, Zhang YLemos B et al. (2017) Tissue accumulation of microplastics in mice and biomarker responses suggest widespread health risks of exposure. Scientific Reports 7: 1-10.

D'Amelia RP, Gentile S, Nirode WF et al. (2016) Quantitative analysis of copolymers and blends of polyvinyl acetate (PVAc) using Fourier transform infrared spectroscopy (FTIR) and elemental analysis (EA). World J Chem Educ 4: 25-31.

Duan G, Zhang C, Li A et al. (2008) Preparation and characterization of mesoporous zirconia made by using a poly (methyl methacrylate) template. Nanoscale Research Letters 3: 118-122.

EFSA panel on contaminants in the food chain-CONTAM. EFSA J (2016);14:e04501. https://doi.org/10.2903/j.efsa.2016.4501.

Fleming M, Ravula S, Tatishchev SFet al. (2012) Colorectal carcinoma: Pathologic aspects. Journal of Gastrointestinal Oncology 3: 153.

Galissier T, Schneider C, Nasri S et al. (2016) Toxicity of microplastics and nanoplastics in mammalian systems. PLoS One 11: e0154326.

Gulmine J, Janissek P, Heise H et al. (2002) Polyethylene characterization by FTIR. Polymer Testing 21: 557563.

Haris M, Kathiresan S, Mohan S (2010) FT-IR and FT-Raman spectra and normal coordinate analysis of poly methyl methacrylate. Der Pharma Chemica 2: 316-323.

Hermsen E, Pompe R, Besseling E et al. (2017) Detection of low numbers of microplastics in North Sea fish using strict quality assurance criteria. Marine Pollution Bulletin 122: 253-258. 
Jung MR, Horgen FD, Orski SV et al. (2018) Validation of ATR FT-IR to identify polymers of plastic marine debris, including those ingested by marine organisms. Marine Pollution Bulletin 127: 704-716.

Käppler A, Fischer D, Oberbeckmann S et al. (2016) Analysis of environmental microplastics by vibrational microspectroscopy: FTIR, Raman or both? Analytical and Bioanalytical Chemistry 408: 83778391.

Kida T, Hiejima Y, Nitta KH (2016) Raman spectroscopic study of high-density polyethylene during tensile deformation. Int J Exp Spectroscopic Tech 1:001.

Koelmans AA, Nor NHM, Hermsen E et al. (2019) Microplastics in freshwaters and drinking water: Critical review and assessment of data quality. Water Research 155: 410-422.

Lefakane T, Ndibewu P, Netshiozwi T (2015) Characterization, Chemical Phase Identification, and Performance Evaluation of Omnipotent Polymers Used in the Manufacturing of Personal Protective Garments. Polymers Research Journal 9: 407.

Li B, Ding Y, Cheng X et al. (2020) Polyethylene microplastics affect the distribution of gut microbiota and inflammation development in mice. Chemosphere 244: 125492.

Mak CW, Tsang YY, Leung MML et al. (2020) Microplastics from effluents of sewage treatment works and stormwater discharging into the Victoria Harbor, Hong Kong. Marine Pollution Bulletin 157: 111181.

Mármol I, Sánchez-de-Diego C, Pradilla Dieste A et al. (2017) Colorectal carcinoma: a general overview and future perspectives in colorectal cancer. International Journal of Molecular Sciences 18: 197.

Menchaca C, Alvarez-Castillo A, Martinez-Barrera G et al. (2003) Mechanisms for the modification of nylon 6, 12 by gamma irradiation. International Journal of Materials and Product Technology 19: 521529.

Pan Z , Sun X, Guo H et al (2019) Prevalence of microplastic pollution in the Northwestern Pacific Ocean. Chemosphere 225:735-744.

Petersen F, Hubbart JA (2021) The occurrence and transport of microplastics: The state of the science. Sci Total Environ 758: 143936.

Schwabl P, Köppel S, Königshofer P et al. (2019) Detection of various microplastics in human stool: a prospective case series. Annals of Internal Medicine 171: 453-457.

Sigma Technical Document. https://www.sigmaaldrich.com/technical-documents/articles/biology/irspectrum table.html (Last access date:12 March 2021).

Smith M, Love DC, Rochman CM et al. (2018) Microplastics in seafood and the implications for human health. 
Stock V, Böhmert L, Lisicki E et al. (2019) Uptake and effects of orally ingested polystyrene microplastic particles in vitro and in vivo. Arch Toxicol 93: 1817-1833.

Thermofisher Application Note. https://assets.thermofisher.com/TFS-Assets/MSD /Application-Notes/A N53001 in-situ-density-determination-pe-polymer-films-raman-microscopy.pdf (Last access date:12 March 2021)

Vasanthan $N$ (2012) Crystallinity determination of nylon 66 by density measurement and fourier transform infrared (FTIR) spectroscopy. Journal of Chemical Education 89: 387-390.

Vijayakumari G, Selvakumar N, Jeyasubramanian K et al. (2013) Investigation on the Electrical Properties of Polymer metal Nanocomposites for Physiological sensing applications. Physics Procedia 49: 67-78.

Wright SL, Kelly FJ (2017) Plastic and human health: a micro issue? Environmental Science \& Technology 51 6634-6647.

Xu JL, Thomas KV, Luo Z et al. (2019) FTIR and Raman imaging for microplastics analysis: State of the art, challenges and prospects. TrAC Trends in Analytical Chemistry 119: 115629.

Yong CQY, Valiyaveetill S, Tang BL (2020) Toxicity of microplastics and nanoplastics in mammalian systems. International Journal of Environmental Research and Public Health 17: 1509.

\section{Figures}

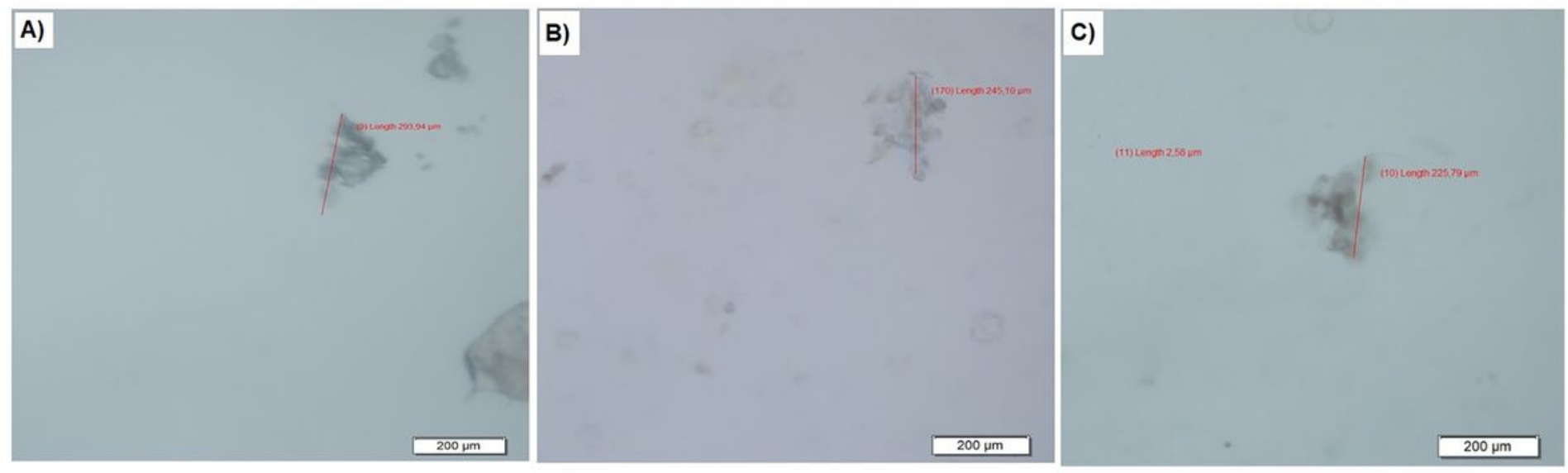

\section{Figure 1}

The representative images obtained using the optical microscope of the extracted microplastic particles from the colon tissue samples of the TCT (a), N-TCT (b), and C (c) groups. 


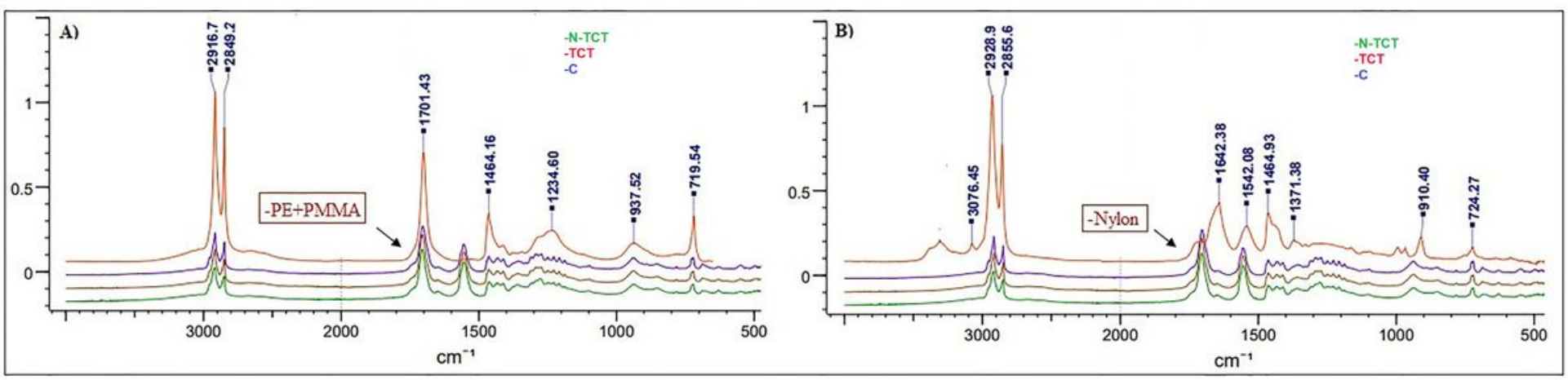

Figure 2

The representative images of the comparison of the obtained ATR-FTIR spectra of the microplastic particles extracted from the tissues (C, TCT, or N-TCT groups) in our study with the spectra in KnowltAll ${ }^{\circledR}$ QC Expert software database [A). PE+PMMA spectra, B). Nylon (polyamide) spectra].

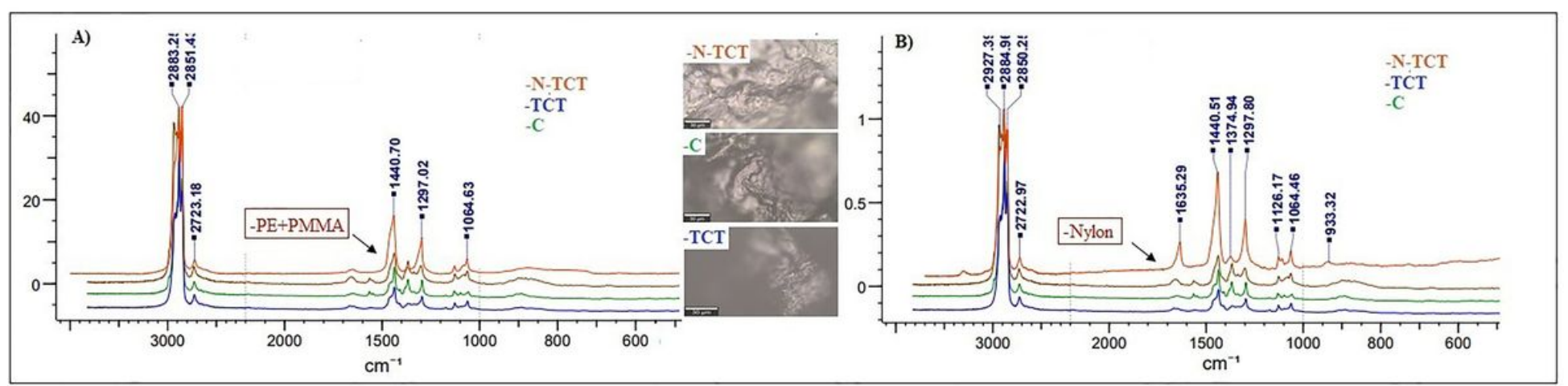

Figure 3

The representative images of comparing the obtained Raman spectra of the microplastic particles extracted from the tissues (C, TCT, or N-TCT groups) in our study with the spectra in the KnowltAll ${ }^{\circledR} \mathrm{QC}$ Expert software database [A). PE+PMMA spectra, B). Nylon (polyamide) spectra]. 